\title{
Chronic toxicity bioassay with ampularid snail Pomacea lineata (Spix 1824) (Mollusca: Prosobranchia)
}

\author{
Luiz Eduardo Lima Melo ${ }^{1}$, Ronilson José da Paz ${ }^{2}$, José Etham de Lucena \\ Barbosa $^{3}$, Takako Watanabe ${ }^{4}$, Judith Font Batalla ${ }^{4}$ and Robert Anthony \\ Coler ${ }^{4}$
}

${ }^{1}$ Instituto Federal de Educação, Ciência e Tecnologia do Rio Grande do Norte (IFRN). Av. Senador Salgado Filho, 1559, Tirol, CEP 59015-000, Natal, RN, Brazil. E-mail: luiz.melo@ifrn.edu.br.

${ }^{2}$ Instituto Brasileiro do Meio Ambiente e dos Recursos Naturais Renováveis (IBAMA), Caixa Postal 5063, CEP 58051-900, João Pessoa, PB, Brazil. E-mail: ronilson.paz@gmail.com.

${ }^{3}$ Universidade Estadual da Paraíba (UEPB), Centro de Ciências Biológicas e da Saúde, Departamento de Biologia, Rua Baraúnas, 351, Campus Universitário, CEP 58429-500, Campina Grande, PB, Brazil. E-mail: ethambarbosa@hotmail.com.

${ }^{4}$ Universidade Federal da Paraíba (UFPB), Centro de Ciências Exatas e da Natureza, Departamento de Sistemática e Ecologia, CEP 58051-900, João Pessoa, PB, Brazil.

\begin{abstract}
Pomacea lineata (Spix, 1824), an extremely ubiquitous snail and pest to rice farmers throughout the orient, holds promise as a valuable resource for monitoring water quality in Northeast Brazil. In this paper, we present data to demonstrate its capacity as a test animal to consistently respond to low level herbicide concentrations (Paraquat and Roundup). Growth data to assess chronic toxicity, were generated in only 96 hours. Applying Duncan's test we were able to tentatively approximate a 96 and 192 hour no observed effective concentration (NOEC) and lowest observed effective concentration (LOEC) for Roundup of 1.0 and 2.0 and 0.5 and $1.0 \mathrm{mg} / \mathrm{L}$, respectively (no acute toxicity was observed during 15 days of exposure.) No such estimates could be attempted with Paraquat, however, because every concentration tested was significantly different from the control percent increase in growth even at the lowest concentration tested $(0.005 \mathrm{mg} / \mathrm{L})$ there was an increase in growth that was significantly greater than control levels suggesting a hormetic effect.
\end{abstract}

Keywords: Biomonitoring, herbicide pollution, ecotoxicity.
Received

May 11, 2014

Accepted

June 18, 2014

Released

June 30, 2014

Open Acess Full Text Article

\section{Introduction}

This contribution may be viewed as a sequel to Melo et al. (2000) in which we described a methodology for routinely identifying acute toxicity in suspect water samples using starved neonates of the amphibious gastropod Pomacea lineata. Sprague (1984) observed that susceptibility to pesticides seems particularly affected by a low protein diet. Upon attempting to assess the toxicity of Roundup (a class 3 herbicide), we were unable, however, to achieve a clear distinction between mortality due to the herbicide and that due to starvation for, mortality among the controls was in excess of $10 \%$ in each of the 4 replicates. Consequently we sought other measures to gauge the organism's sensitivity. One such tactic, which seemed a 
nonsequitur at the time, was to initiate feeding. It would appear that feeding an already resistant species would make it yet more capable of mobilizing some homeostatic mechanism and even less sensitive to stress. The choice, however, proved to be serendipitous for the impact on percent increase in growth yielded a more rapid and finer resolution of response than mortality.

The fact that this response was achieved in acute toxicity time frames makes the protocol particularly pertinent to water monitoring in Northeast Brazil, a tropical region comprised of 9 states, beset by chronic drought and poverty. Virtually all water comes from impoundments which are invariably exploited jointly for irrigation and drinking water. The watersheds in the Littoral Zone are farmed down to their receding water levels during the 6 months of scant rainfall when the reservoirs shrink to a fraction of their capacity. With the advent of the rains, excessive runoff, and flooding, in concert with unregulated herbicide applications and fertilizer enrichment conspire to foster a eutrophied, marginal environment dominated by cyanophytes (Barbora et al., 2014). Sampling need be rigorous, reflecting frequency, toxicity and concentration of pesticide applied, as well as runoff, slope, area of cultivated land, and proximity to water.

Water quality surveys are strongly indicated but the northeast is without the financial resources and sophistication to mount an ongoing instrumentation based surveillance program. Biomonitoring (benthic macroinvertebrate surveys and bioassays) remains the only option for quality assurance, but species diversity determinations are not viable alternatives because macroinvertebrate taxonomic keys for the region have not been developed. The alternative then lies with bioassay, but not with the traditional time honored method but one that affords rapid processing of suspect samples. In short there is a need to identify emerging crises, a kind of a triage that rapidly provides a yes or no answer to a pesticide application regime. It may be that we have found such a tool in Pomacea lineata used in conjunction with modified 'standard' bioassay techniques. This protocol is offered not as a refinement but as an expedient. Paraíba alone has 7.000 impoundments greater than a hectar in area (Watanabe et al., 1999). To date there have been no pollution surveys nor are any anticipated.

\section{Method}

According to USEPA (1997), Paraquat Dichloride is an herbicide currently registered to control weeds and grasses in many agricultural and nonagricultural areas. It is used preplant or preemergence on vegetables, grains, cotton, grasses, sugar cane, peanuts, potatoes, and tree plantation areas; postemergence around fruit crops, vegetables, trees, vines, grains, soybeans, and sugar-cane; during the dormant season on clover and other legumes; as a desiccant or harvest aid on cotton, dry beans, soybeans, potatoes, sunflowers, and sugar cane; and as a post harvest desiccant on staked tomatoes.

Glyphosate is a non-selective herbicide registered for use on many food and non-food field crops as well as noncrop areas where total vegetation control is desired (USEPA, 1993). Glyphosate herbicides such as brands of Roundup, are known to be toxic to daphnids (Cuhra et al., 2013).

In Northeast Brazil, Paraquat and Roundup are herbicides widely used in agriculture, in sugar-cane fields, and the cultivation of pineapple and Eucalyptus (Gadelha et al., 2001).

The methodology employed to assay chronic toxicity of Paraquat and Roundup generally conformed to the appropriate sections listed in Eaton et al. (1995). In those instances where they were modified they followed the procedures outline by Buikema et al. (1980) for Daphnia similis, Batalla (1997), Melo et al. (2000) and Coler et al. (2005) for the snail Pomacea lineata, and Aragão et al. (1998) and Coler et al. (1999) for the prawn Macrobrachium amazonicum.

The test specimens were treated as described by Melo et al. (2000) with the exception that the neonates were maintained on a feeding regime and the endpoints adopted were weight gain as percent increase over initial weight instead 
of as percent survival. The ration consisted of a mixture of equal portions by weight of ground fish, wheat, soy and corn flour steamed, agglutinated with mandioca flour, dried and pulverized.

The food was sprinkled in excess on the surface of each replicate 4 hours before the daily renovation of test solutions, at which time immobile organisms that failed within 5 minutes exposure to respond to intense light or pricking were removed. The collective weight of each treatment replicate (15 individuals) was determined at the initiation of each experiment and for Paraquat and Roundup respectively, 4 or 4 and 8 days after.

To determine the accuracy of the weighing procedure, we selected 5 neonates and weighed them 10 consecutive times, each time returning them to the water, retrieving them, blotting them dry and weighing them. Variation of the average weight $(0.058 \mathrm{~g})$ was described with confidence intervals $(0.00083)$ and coefficient of variation (0.023). Four replicates of 15 organisms each were employed for each treatment. The test of significance used was Duncan's multiple range test. Statistics were based on nominal concentrations due to the unavailability of analytical instrumentation. Each test was performed with 5 (Roundup) or 4 (Paraquat) replicates of 15 neonates for (Paraquat) or 8 (Roundup) days.

\section{Results and Discussion}

A comparison of the data generated by testing starved (Melo et al., 2000) and fed neonates of Pomacea lineata exposed to similar ranges of Paraquat concentrations, reveals some interesting relationships. While the starved treatment produced $100 \%$ mortality within 4 to 7 days at concentrations from 2 to $0.5 \mathrm{mg} / \mathrm{L}$, there was no mortality observed among those provided ration for 4 days at concentrations varying in multiples of 2 from 0.005 to 1 $\mathrm{mg} / \mathrm{L}$. This is as might be expected because the only mortality observed in the starved treatment within 4 days was at $2 \mathrm{mg} / \mathrm{L}$ $(100 \%)$ and $1 \mathrm{mg} / \mathrm{L} \quad(75 \%)$. What is noteworthy, however is the agreement between the two endpoints (death and growth) when exposed to the same range of concentrations for 15 and 4 days (respectively) of toxicity testing. Confidence intervals (CI) of the 0.07 (survival) and 0.05 (growth) dilution overlap broadly with those of the control in the 2 treatments and appear to be good approximations of the NOEC (no observed effective concentration). If one considers that during the first week of the starved treatment $100 \%$ of the 2.0, 1.0, 0.7 and 0.5 $\mathrm{mg} / \mathrm{L}$ dilutions died (Melo et al., 2000), it seems noteworthy that growth was obtained in the present research at these concentrations and that the gradient was linear (Figure 1).

Extrapolating from these acute toxicity data would yield an EC50 (effective concentration that reduces indicated life process by 50\%) (growth) for Paraquat of $0.7 \mathrm{mg} / \mathrm{L}$, a concentration which causes $100 \%$ mortality in 6 days. Historically the EC50 has been perceived as an estimate that indicated some diminished sublethal but still biologically functional process (Rand and Petrocelli, 1984). On the basis of survival this EC50 estimate places the organism at an extremely tenuous level of existence. A more biologically meaningful index would be closer to an EC90 (effective concentration that reduces indicated life process by $90 \%$ ).

A review of the Roundup data reveals growth inhibition at all treatments. The Duncan's test demonstrates significant differences between the control and all treatments (Table 2). The fact that a $4 \mathrm{mg} / \mathrm{L}$ two week exposure to Roundup was not acutely toxic while it was yet possible to attain NOEC levels at $0.12 \mathrm{mg} / \mathrm{L}$ in 4 days attests to the sensitivity of growth as a measure of stress. When the starved treatment was exposed to Roundup for 15 days, however, no mortality was observed that could be attributed to herbicide toxicity. Upon retesting with a feeding regime and weighing, we obtained in 4 days discrete statistically significant growth differences at relatively small increments of dilution (Figure 2). While the percent increase in growth was larger with increased exposure time, the percent increase over time remained constant except at high concentrations. The ratio of the 8 to 4 day percent's increase in growth (Table 3) for 4, 2, 1, 0.5, 0.25, 0.12 and 


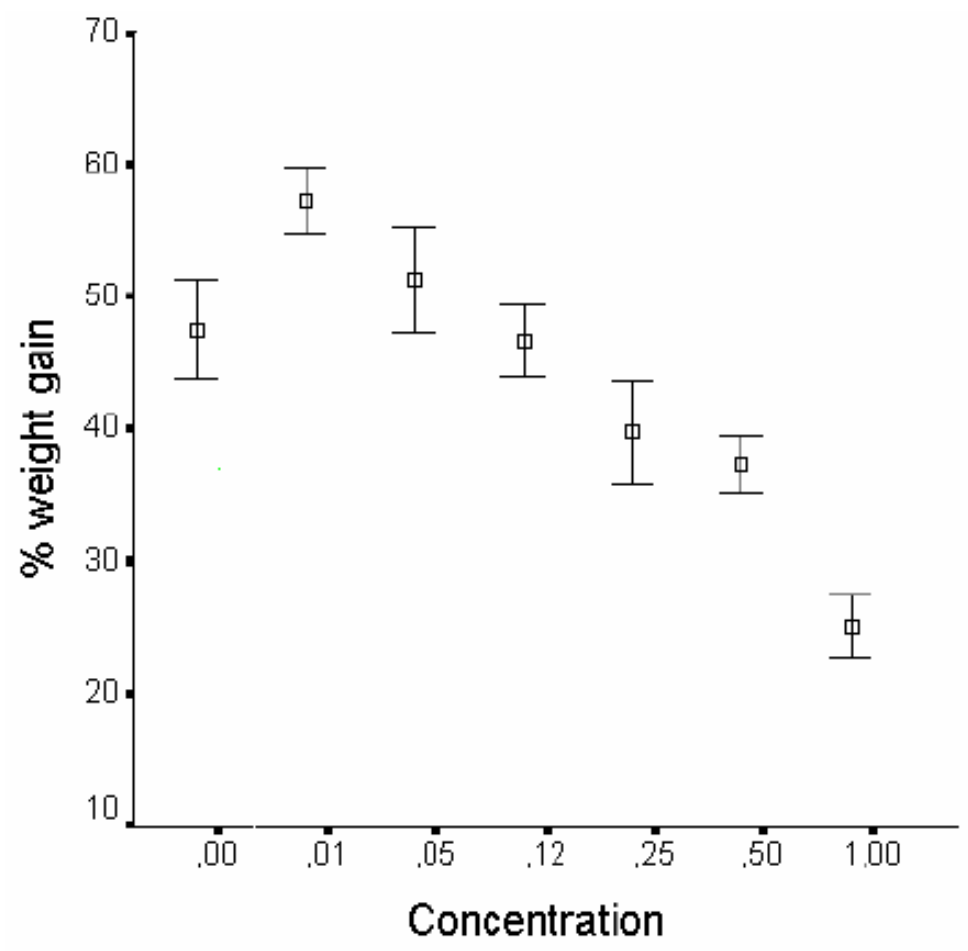

Figure 1. Average percent weight gain (\%) with confidence intervals of four replicates exposed to indicated concentrations ( $\mathrm{mg} . \mathrm{L}^{-1}$ ) of Paraquat for four days.

Table 1. Duncan test for Paraquat data (4 replicates) presented in Figure 1 (four days).

\begin{tabular}{l|ccccccc}
\hline & Control & 1.0 & 0.5 & 0.25 & 0.12 & 0.05 & 0.005 \\
\hline Control & - & $.000024^{*}$ & $.000027^{*}$ & $.000040^{*}$ & $.000140^{*}$ & $.038862^{*}$ & $.004712^{*}$ \\
1.0 & & - & $.005990^{*}$ & $.000076^{*}$ & $.000056^{*}$ & $.000027^{*}$ & $.000033^{*}$ \\
0.5 & & & - & $.027093^{*}$ & $.003756^{*}$ & $.000037^{*}$ & $.000120^{*}$ \\
0.25 & & & & - & $.347748 \S$ & $.002336^{*}$ & $.022199^{*}$ \\
0.12 & & & & & - & $.018836^{*}$ & $.125531 \S$ \\
0.05 & & & & & & - & $.312417^{*}$ \\
0.005 & & & & & & & - \\
\hline
\end{tabular}

Marked differences $(*)$ are significant at $\mathrm{p}<0.05 ; \S=$ not significant.

Table 2. Duncan test for Roundup data presented in Figure 2 (eight days).

\begin{tabular}{c|ccccccc}
\hline & Control & 4.0 & 2.0 & 1.0 & 0.5 & 0.25 & 0.12 \\
\hline Control & - & $.000025^{*}$ & $.000058^{*}$ & $.001181^{*}$ & $.003873^{*}$ & $.063496 \S$ & $.023804^{*}$ \\
4.0 & & - & $.211550 \S$ & $.016702^{*}$ & $.005664^{*}$ & $.000219^{*}$ & $.000790^{*}$ \\
2.0 & & & - & $.177656 \S$ & $.078528 \S$ & $.004605^{*}$ & $.015224^{*}$ \\
1.0 & & & & - & $.593367 \S$ & $.081401 \S$ & $.197956 \S$ \\
0.5 & & & & & - & $.188720 \S$ & $.399654 \S$ \\
0.25 & & & & & & - & $.573260 \S$ \\
0.12 & & & & & & & - \\
\hline
\end{tabular}

Marked differences $(*)$ are significant at $\mathrm{p}<0.05 ; \S=$ not significant. 


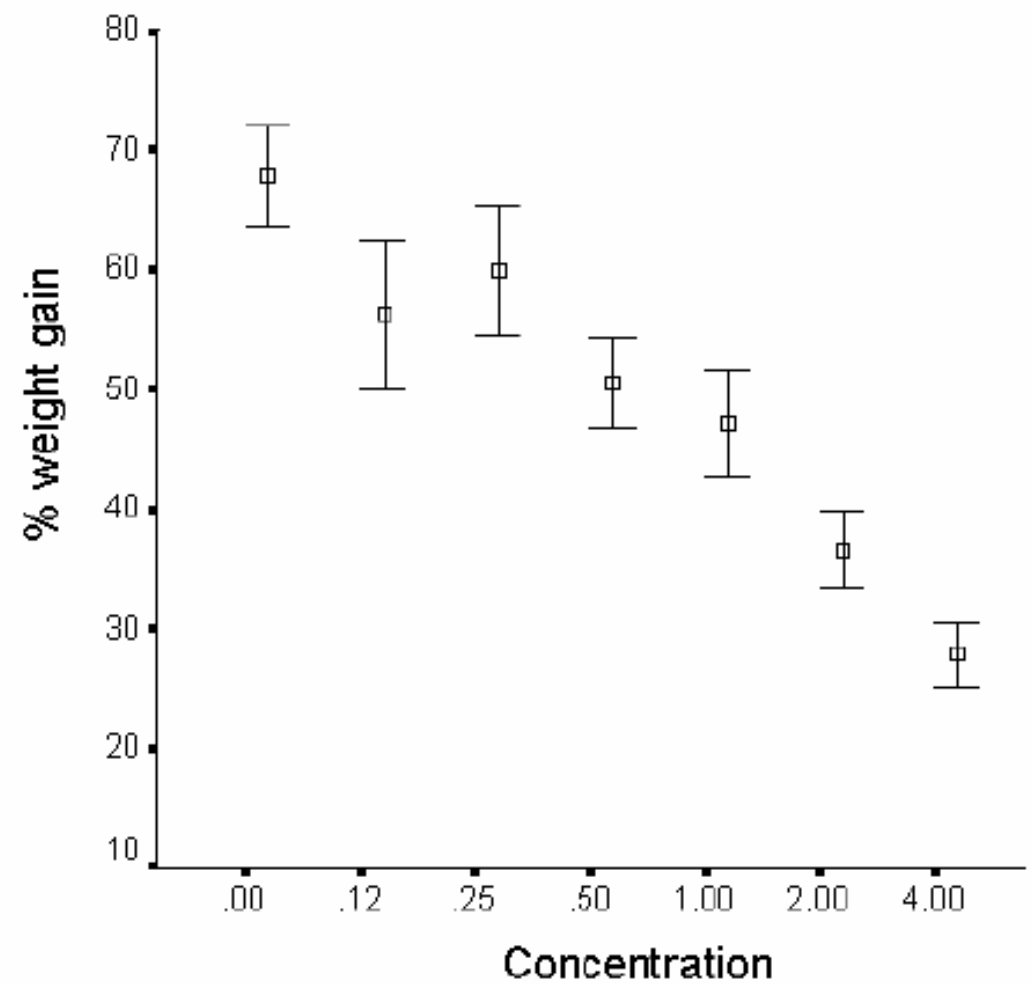

Figure 2. Average percent weight gain (\%) with confidence intervals of five replicates exposed to indicated concentrations $\left(\mathrm{mg} . \mathrm{L}^{-1}\right)$ of Roundup for eight days.

Table 3. Average percent increse in weight with confidence intervals (CI) and coefficients of variations (CV) of Pomacea lineata neonates after 4 and 8 days exposure to indicate concentrations (mg. $\mathrm{L}^{-1}$ ) of Roundup (5 replicates of 20 individuals per treatment).

\begin{tabular}{c|cccccc}
\hline \multirow{2}{*}{ Conc. } & \multicolumn{3}{|c}{ 4 days } & \multicolumn{3}{c}{ 8 days } \\
\cline { 2 - 7 } & Average & CI & CV & Average & CI & CV \\
\hline 0.0 & 36.9 & 4.4 & 0.14 & 67.8 & 4.6 & 0.07 \\
0.12 & 30.2 & 4.8 & 0.18 & 56.2 & 6.3 & 0.12 \\
0.25 & 31.7 & 2.9 & 0.11 & 59.5 & 3.7 & 0.10 \\
0.5 & 27.9 & 2.6 & 0.11 & 50.5 & 3.7 & 0.80 \\
1.0 & 26.4 & 2.8 & 0.11 & 47.1 & 3.7 & 0.80 \\
2.0 & 22.7 & 2.4 & 0.12 & 38.6 & 3.3 & 0.10 \\
4.0 & 19.3 & 2.4 & 0.14 & 27.9 & 2.7 & 0.11 \\
\hline
\end{tabular}

$0 \mathrm{mg} / \mathrm{L}$ were respectively $1.44,1.64,1.78$, $1.81,1.89,1.86$ and 1.84. All treatment growth rates are significantly different from the control (Figure 2). The data indicate that with routine sample processing time could be complete in 4 days. When testing for less virulent herbicides, to achieve greater resolution, it may be necessary, however, to increase the replicate number to 5 and the exposure period to 8 days.
While 8 days were neceessary to achieve a clearly defined differentiation among the test concentrations of Roundup, only 4 were required for the more toxic Paraquat (Figure 1 and Table 1). Pomacea when exposed to Paraquat and Roundup at lower concentrations appears to overcompensate with heightened growth rates at 0.005 and $0.25 \mathrm{mg} / \mathrm{L}$ respectively that are statistically significant. According to Calabrese and Baldwin (1993) such 
responses might describe the mechanism for hormesis. There is an insufficient data base, however, to support anything but speculation. As presently anticipated the standard protocol would be to prepare a $100 \%, 50 \%$ and $0 \%$ (control) set of dilutions replicated 5 times with 15 organisms/replicate. Each of the treatment replicates would be weighed initially and 4 days after. If there are no significant differences in percentual weight gain from the control according to the Duncan test for significant differences, the sample is cleared. If the data are equivocal, the experiment is continued for another 4 day interval with weighing. If in the event toxicity is detected, the LOEC/NOEC thresholds of that herbicide on both starved and fed neonates (as a fail safe tactic) are determined according to the method outlined by Melo et al. (2000) with the limnetic lake water as the diluent. The toxicity of the undiluted test sample will be matched against that of 6 prepared dilutions and a control (each dilution is 0.7 the concentration of its predecessor) and reported as some multiple of the NOEC. [Once the bioassay is undertaken for any particular herbicide and a LOEC/NOEC generated, it need not be repeated for that region.] In this manner the pollution control agency is provided with a benchmark to evaluate conformity to recommended procedures. The uniqueness of this protocol lies in the ease with which chronic toxicity data can be rapidly processed in a basic laboratory by untrained personnel with only a balance, glassware and a supply of control quality water without compromising data sensitivity or reproducibility. Subsequently other test animals will be added after the sampling procedure is refined. In this regard we are presently considering the prawn Macrobrachium amazonicum (Coler et al., 1999), the angiosperm Lemna minor (Tabosa, 2000), the periphyton Selanastrum capricornutum (Rocha et al., 1998) and the zooplankton Daphnia similis. The limiting factor in identifying and adopting suitable candidates is not the biology of the species but the expense and the sophistication demanded by the technique. Consequently, the size of the 'stable' will depend on the capacities of each regional laboratory.
Abbreviations: LOEC $=$ lowest observed effective concentration. NOEC $=$ no observed effective concentration.

\section{References}

Aragão, R. M.; Xavier, B.; Coler, R.; Watanabe, T. A preliminary study of respiration and excretion rates in prawn Macrobrachium amazonicum when exposed to varied flow regimes and salinities. Rev. Nordestina Biol., v. 12, p. 1-8, 1998.

Barbosa, J. E. L.; Watanabe, T.; Coler, R. A.; Paz, R. J. Biota toxicity to herbicide Paraquat in Brazilian Northeast littoral reservoirs: need for a biomonitoring program for watershed management. Brazilian Journal of Biological Sciences, v. 1, p. 21-27, 2014.

Batalla, J. F. Efeito do herbicida Paraquat sobre o gastrópode Pomacea lineata (Spix, 1827) (Ampullariidae, Prosobranchia): Bioensaios em laboratório. João Pessoa: Universidade Federal da Paraíba, 1997. (Masters Thesis).

Buikema， A. L.; Geiger， J. G.; Lee, D. R. Daphnia toxicity tests. Aquatic Invertebrate Bioassays, v. 3, p. 48-69, 1980.

Bustos-Obregon, E.; Vargas, Á. Chronic toxicity bioassay with populations of the crustacean Artemia salina exposed to the organophosphate diazinon. Biol. Res., v. 43, p. 357-362, 2010.

Calabrese, E. J.; Baldwin, L. Possible examples of chemical hormesis in a previously published study. J. Appl. Toxicol., v. 13, p. 169-172, 1993.

Coler, R. A.; Coler, R. R.; Felizardo, E. K. G.; Watanabe, T. Applying weight gain in Pomacea lineata (Spix, 1824) (Mollusca: Prosobranchia) as a measure of herbicide toxicity. Braz. J. Biol., v. 65, p. 617-623, 2005.

Coler, R. A.; Watanabe, T.; Xavier, B. F.; Paz, R. J. A preliminary report on the application of Macrobrachium amazonicum Heller, 1862 (Decapoda: Palaemonidae) as a biomarker. Hydrobiologia, v. 412, p.119-121, 1999.

Cuhra, M.; Traavik, T.; Bøhn, T. Clone- and age-dependent toxicity of a glyphosate commercial formulation and its active ingredient in Daphnia magna. Ecotoxicology, v. 22, p. 251-262, 2013.

Eaton, A. D.; Clesceri, L. S.; Greenberg, A. E. (Ed.). Standard Methods for the Examination of Water \& Wastewater. New York: American Public Health Association Publications, 1995.

Gadelha, C. L. M.; Filgueira, H. J. A.; Campos, L. F.; Quinino, U. C. M. O uso de agrotóxicos 
nas áreas irrigadas da Bacia do Rio Gramame no Estado da Paraíba. Anais do $21^{\circ}$ Congresso Brasileiro de Engenharia Sanitária e Ambiental, Rio de Janeiro, 2001. 6 p.

Medeiros, V. M.; Watanabe, T.; Coler, R. R.; Coler, R. A. Development of methods to assess the impact of herbicide use on the benthos of littoral impoundments in Northeast Brazil. Journal of Aquatic Ecosystem Stress and Recovery, v. 9, p. 67-71, 2001.

Melo, L. E. L.; Coler, R. A.; Watanabe, T.; Batalla, J.F. Developing the gastropod Pomacea lineata (Spix, 1827) as a toxicity test organism. Hydrobiologia, v. 429, p. 73-78, 2000 .

Rand, G. M.; Petrocelli, S. R. (Ed.). Fundamentals of Aquatic Toxicology. Washington: MacGraw Hill, 1995.

Rocha, T. R. P.; Watanabe, T.; Sassi, R.; Coler, R. A. The photosynthetic/respiratory response of a periphytic population (Selenastrum capricornutum) to Paraquat as a biomarker. Acta Limnol. Brasil., v. 10, p. 131-136, 1998.
Sprague, J. B. Factors that modify toxicity. In: Rand, G. M.; Petrocelli, S. R. (Ed.). Fundamentals of Aquatic Toxicology. Washington: MacGraw Hill, 1995. p. 125-167.

Tabosa, W. A. F. Bioensaios com Lemna minor (Linnaeus, 1753), um estudo da toxicidade de um efluente industrial no Rio Gramame. João Pessoa: Universidade Federal da Paraiba, 2000. (Masters Thesis).

USEPA - United States Environmental Protection Agency. R.E.D. Facts: Glysophate. Washington DC: USEPA Offices of Prevention, Pesticides And Toxic Substances, 1993.

USEPA - United States Environmental Protection Agency. R.E.D. Facts: Paraquat Dichloride. Washington DC: USEPA Offices of Prevention, Pesticides And Toxic Substances, 1997.

Watanabe T.; Coler, R. A.; Paz, R. J. The implementation of a regional biomonitoring program in Northeast Brazil. Aquatic Ecosystem Health and Management, v. 2. p. 187-189, 1999. 